EPiC Series in Engineering
Volume 3, 2018, Pages 866-873
HIC 2018. 13th International
Conference on Hydroinformatics

\title{
Integrated Water Resources Management in a Complex Reservoir System through a Multipurpose DSS Tool
}

\author{
Raquel Gómez-Beas ${ }^{1}$, Eva Contreras-Arribas ${ }^{1}$, Sergio Romero ${ }^{2}$, Óscar \\ Lorente $^{3}$, Antonio Linares-Sáez ${ }^{1}$ and Laura Panizo ${ }^{4}$ \\ ${ }^{1}$ Abengoa Water, Energía Solar, Campus Palmas Altas, Seville, Spain \\ ${ }^{2}$ Software for Critical Systems, Arquitecto Francisco Peñalosa, Málaga, Spain \\ ${ }^{3}$ Consejería de Medio Ambiente y Ordenación del Territorio, Paseo Rending, Málaga, Spain \\ ${ }^{2}$ University de Málaga, Arquitecto Francisco Peñalosa, Málaga, Spain \\ rakelgbeas@gmail.com, econtreras@uco.es, sromero@softcrits.es, \\ oalberto.lorente@juntadeandalucia.es, antonio.linares@abengoa.com, \\ laurapanizo@lcc.uma.es
}

\begin{abstract}
Water resources management requires the integration of many complex physical processes, as well as the interaction of many stakeholders, to ensure the sustainable use of surface and groundwater resources. Water problems to which water authorities have to face are water deficit to supply a wide and increasing demand, floods, water pollution, leaks in water distribution infrastructures, and optimization in the energy use and production. A comprehensive and detailed analysis of the availability of water resources in terms of quantity and quality, and of water demand in their variability in space and time, is indispensable. In this context, SAID (SmArt water management with Integrated Decision support systems) project addresses the development, implementation, validation and integration of the most innovative DSSs as the basis for smart water management systems in complex basins. This paper focuses on the methodology carried out to integrate multipurpose aspects involved in the management of water resources in Guadalhorce River Basin (southern Spain), as a demonstrator area. As a support in the decision making process to dam managers, the resulting integrated DSS allows to execute predictive simulations to anticipate the watershed response, considering two types of scenarios (flood and ordinary), driven by different optimization criteria.
\end{abstract}




\section{Introduction}

The complex interactions between human society and water resource systems, as well as the rapidly increasing in the use of water resources, forces many countries to face the task of achieving higher levels in water management planning and in the control of ongoing hydrological processes. Despite the great potential market of smart ICT solutions in this area, the low number of deployed DSSs typically focus on isolated and uncoordinated water systems to manage specific functions or elements like reservoir dams, flood prevention dams, irrigation infrastructures, hydropower plants, pumping stations for water supply, water of quality monitoring stations, etc. With the proliferation of new DSSs for specific problems, the integration of DSSs can provide additional benefits. In recent years, multidisciplinary integrated modelling has become an area of great interest, not only for researchers and institutions (Bithel and Brasington 2009), but also for international research alliances (van Ittersum, et al. 2008). Besides, different approaches have been used to optimize the operation policy in multipurpose reservoirs, for instance Genetic Algorithms (Ahmed and Sarma 2005), NeuroDynamic Programming (Castelletti, et al. 2007), Artificial Bee Colony and Gravitational Search Algorithms (Ahmadi, Bozorg Haddad and Mariño 2014), Evolutionary Multi-Objective Direct Policy Search (Zatarain-Salazar, et al. 2016). Despite the great effort made in the development of models that tackle the optimization of the operation policies, still few of them provide real-time information of the water resources in the whole basin as an integrated approach. Moreover, DSS may be used in water supply management where these tools can take current climate forecast, and combine hydrologic, hydraulic and water quality models into real-time reservoir systems optimization models.

Focusing on the idea of more integration at the methodological and technical levels, SAID project (SmArt water management with Integrated Decision support systems) (SAID Consortium 2017) has focused on the deployment and evaluation of a complex demonstrator, composed by several heterogeneous and innovative DSS tools in the same river basin, providing validated tools to reduce flood risks and its effects, to enhance the quality of water for urban and irrigation purposes and to reduce the cost of energy in water related processes. This paper focuses on the methodology carried out to integrate multipurpose aspects involved in the management of water resources in the demonstration area of the project.

\section{Material and methods}

\subsection{Demonstration area}

The demonstration area is the Guadalhorce River Basin located in the South of Spain (see Figure 1(a), which comprises 3 headwater reservoirs: Guadalhorce reservoir (Dams 1), Guadalteba reservoir (Dam 2) and Conde del Guadalhorce reservoir (Dam 3) in Figure 1(b), but also La Encatada reservoir (Dam 4) that collects water from the 3 upstream reservoirs and distributes it to supply the water demands. Besides of hydroelectric exploitation purposes, reservoirs supply all water uses: urban, irrigation, energy and ecology, of a population around 650,000 inhabitants, with a strong seasonal variability associated to tourism in the zone ( $>1,2$ million inhabitants in summer). Due to Mediterranean climate, this area is subjected to long drought periods followed by strong flood episodes which have particular territorial effects with broad socio-economic and environmental impacts. Moreover, the main water quality problem is the high salinity concentration (more than $5.000 \mu \mathrm{S} / \mathrm{cm}$ ) in one of the reservoirs (Dam 1) due to the contribution of a saline aquifer. Therefore, the main water problems faced in the Guadalhorce basin infrastructure are: a) urban water supply deficit; b) high salinity due to the saline groundwater; c) energy production in hydroelectric plants and consumption in pumping stations; and d) flood areas with their associated impacts. The complexity of 
this river basin means it is an ideal candidate to validate the methods and tools for smart water management.

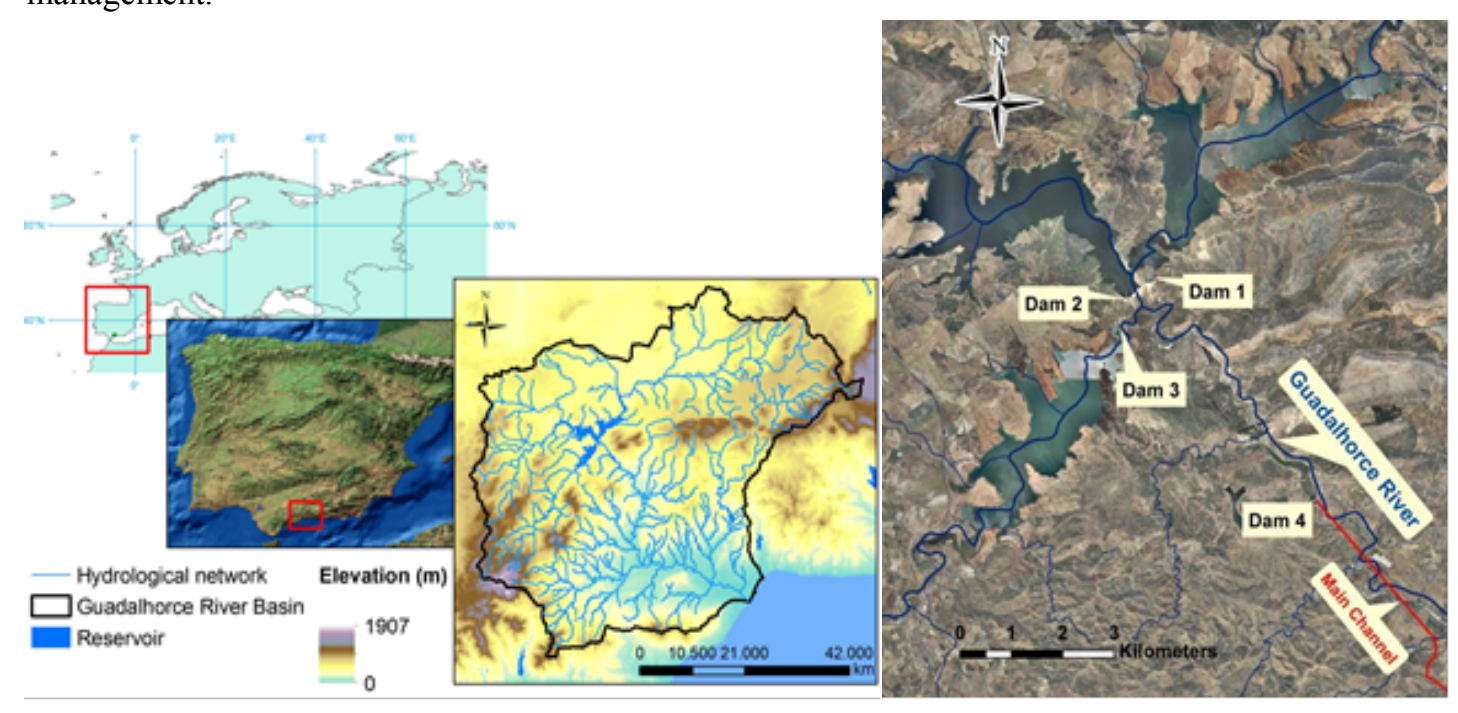

Figure 1: (a) Location of Guadalhorce River Basin (b) Guadalhorce reservoir system

\subsection{Development of DSS tools}

First of all, the development and implementation of DSS tools need to be supported by automatic sensor networks, which allow the knowledge and control for the whole river basin. Thus, a real-time monitoring and communication network has been deployed (Figure 2(a)) as a complement to Hidrosur network which currently works in the area. The deployed monitoring network supports four DSS tools: dam management (DM-DSS) (SAID Consortium 2017, Linares, et al. 2014), flood management (FM-DSS) (SAID Consortium 2017), water quality management (WQ-DSS) (SAID Consortium 2017) and energy management (EM-DSS) (SAID Consortium 2017). The monitoring network is comprised of 2 stations of water level for flood control, 1 station of water flow for environmental flow control, 1 station of water flow for water distribution control and 6 stations of water quality for salinity control (Figure 2(a)). The information is captured and delivered in real-time to a Basin Control Centre.

Secondly, some constraints at flood and ordinary operation need to be defined for the demonstration area. These constraints include flood, water quality and energy aspects (Figure 2(b)).

Finally, with the aim of obtaining simulation results, a new integration has been implemented using unified DSSs. This functional integration determines the expected inputs, outputs and services of each module. Due to requirements inherent in a DSS such as security, interoperability, heterogeneity and distributed computing, standard mechanisms for scalable and interoperable systems based on HTTP (like REST (Webber, Parastatidis and Robinson 2010)) have been used. An exchange of key-value data structures that includes fixed and time-dependent parameters has been required to communicate the DSSs. Therefore, the four DSSs have been modified to publish integration functionality via REST services with JSON serialization. 


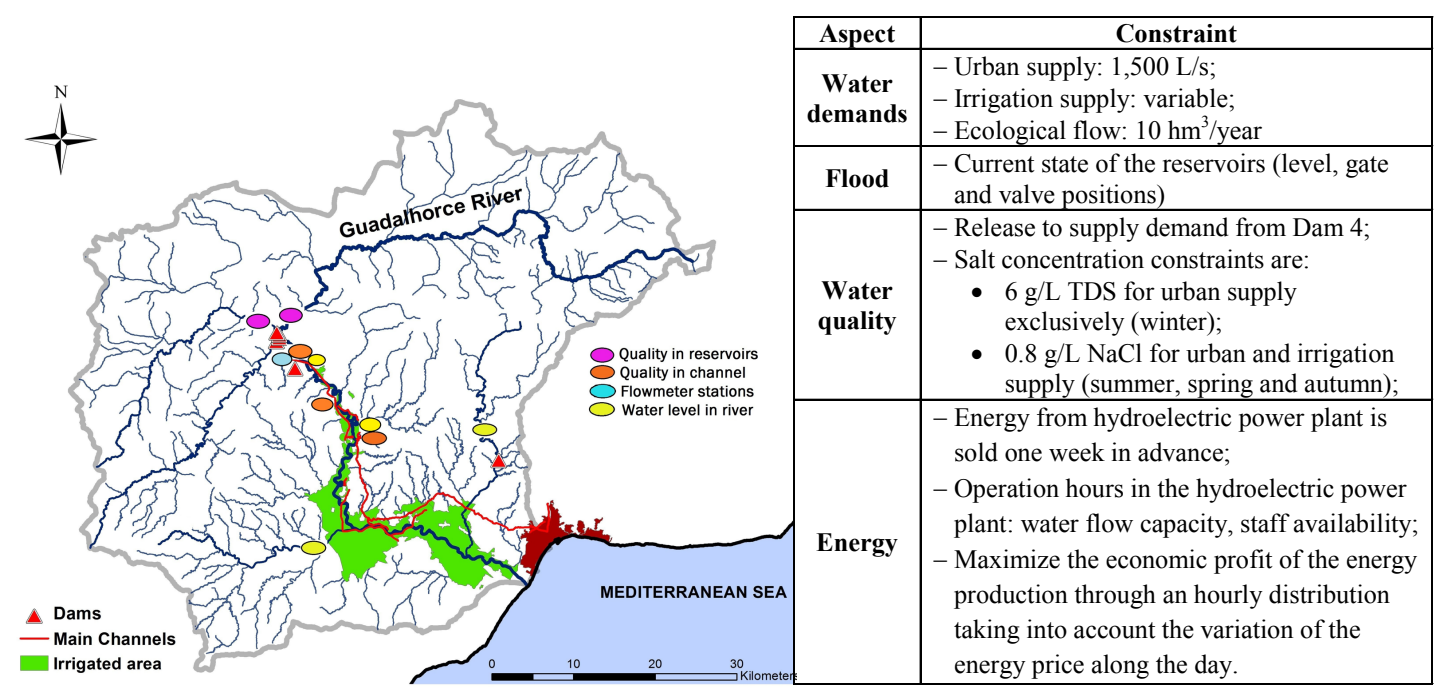

Figure 2: (a) Monitoring stations deployed in the area (b) Constraints to be implemented in the DSS tool

\section{Results and discussions}

The main results of SAID project are software products (DSSs) for managing river basins, reservoirs, irrigation channels and hydroelectric power systems. In addition, policies for integrated management of floods, water demand supply, water quality and optimization of energy production have been defined in the project. These DSS software and modules can be exploited independently or integrated in a platform as a whole.

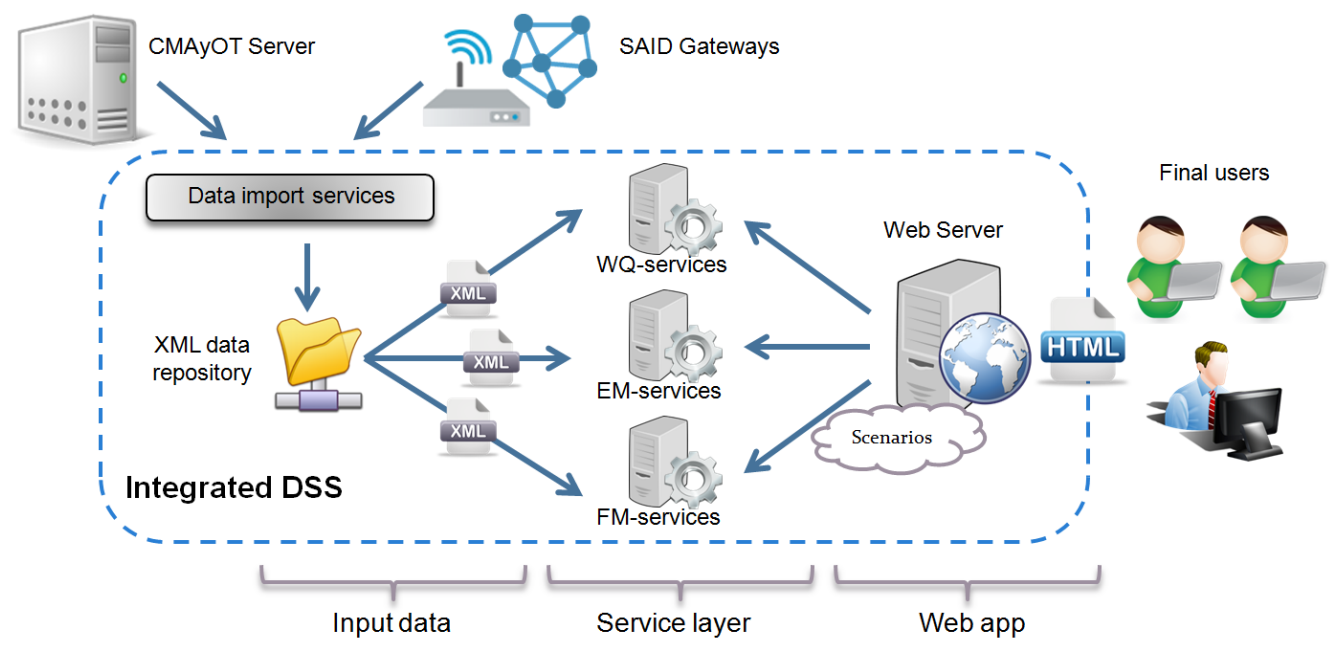

Figure 3: Architecture of the integration platform 
Figure 3 shows the high level architecture of the integration platform, which involves input data (from the real-time monitoring system and data servers), DSS services and a Web application that offers the proper "front-end" for users to drive simulations and inspect the results. The Web application comprises a set of HTML pages to login in the platform, configure the application, visualize the real-time data and the weather forecast, as well as to configure the simulation of different scenarios for flood and ordinary operation (see Figure 4, Figure 5 and Figure 6).

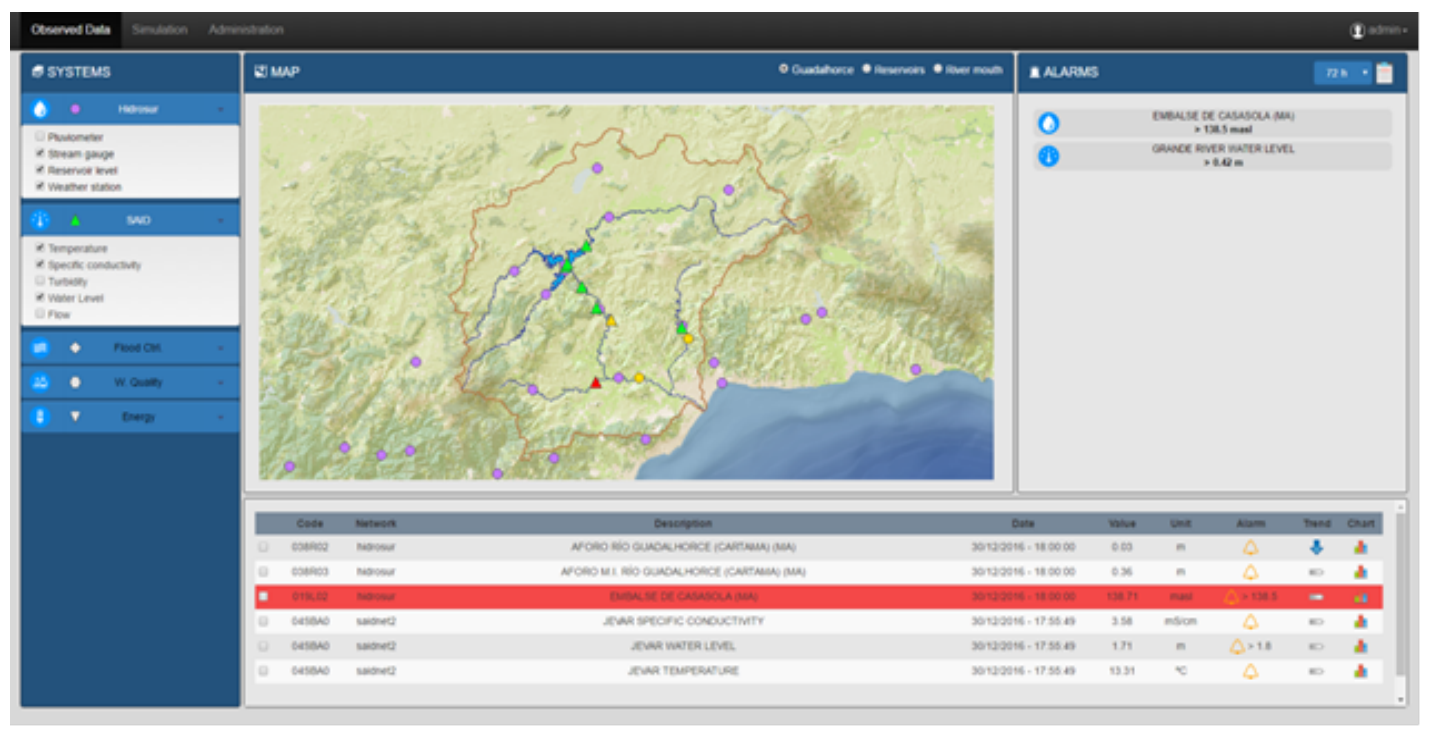

Figure 4: Monitoring networks display in the DSS integrated tool (Web application)

The integrated tool can be run in two scenarios: flood and ordinary operation (Figure 5 and Figure 6). Both scenarios start with the FM-DSS which runs a hydrological model (WiMMed, Watershed Integrated Model in Mediterranean Environments (Herrero, et al. 2011, Polo, et al. 2009, Egüen, et al. 2009) to simulate the reservoir inflow for the next 72 hours, using real time climate forecasts. WiMMed is a complete, distributed physical hydrological model. It uses hourly and daily meteorological data, along with certain physical properties of the soil and subsoil to perform the spatial interpolation and temporal distribution of meteorological variables and soil processes. To do so, WiMMed state is daily updated, in order to obtain realistic results. In this regard, a special platform service is running in the background updating the hydrological model as soon as the next set of 24-hour input data is available. These data refer to monitored values of rainfall, temperature, wind speed and solar radiation, as well as actual reservoir outflows in the last 24 hours. Executing WiMMed as described provides more accurate results for the first step of the integration workflow.

The next step in a flood scenario is the simulation and optimization of the dam maneuvers using DM-DSS, taking into account the current state of the reservoirs (see Figure 2(b)) and the manipulation of the outlets and spillways to control the flood (maneuvers). Different groups of maneuvers are suggested as a result (time outflow series, state of discharge elements), each one characterized by the implementation of different sets of constraints. Criteria such as salinity and energy optimization are ignored, as the priority is to keep populations and dams safe from danger. The next step entails downstream simulations addressed by FM-DSS, running a hydrodynamic model, which calculates the flood plain and water flow at predefined locations. Finally, the Web application (Figure 5) shows the users the potential effects of suggested flood control methods. A special emphasis is put on those data that are more relevant from the basin manager's viewpoint. 


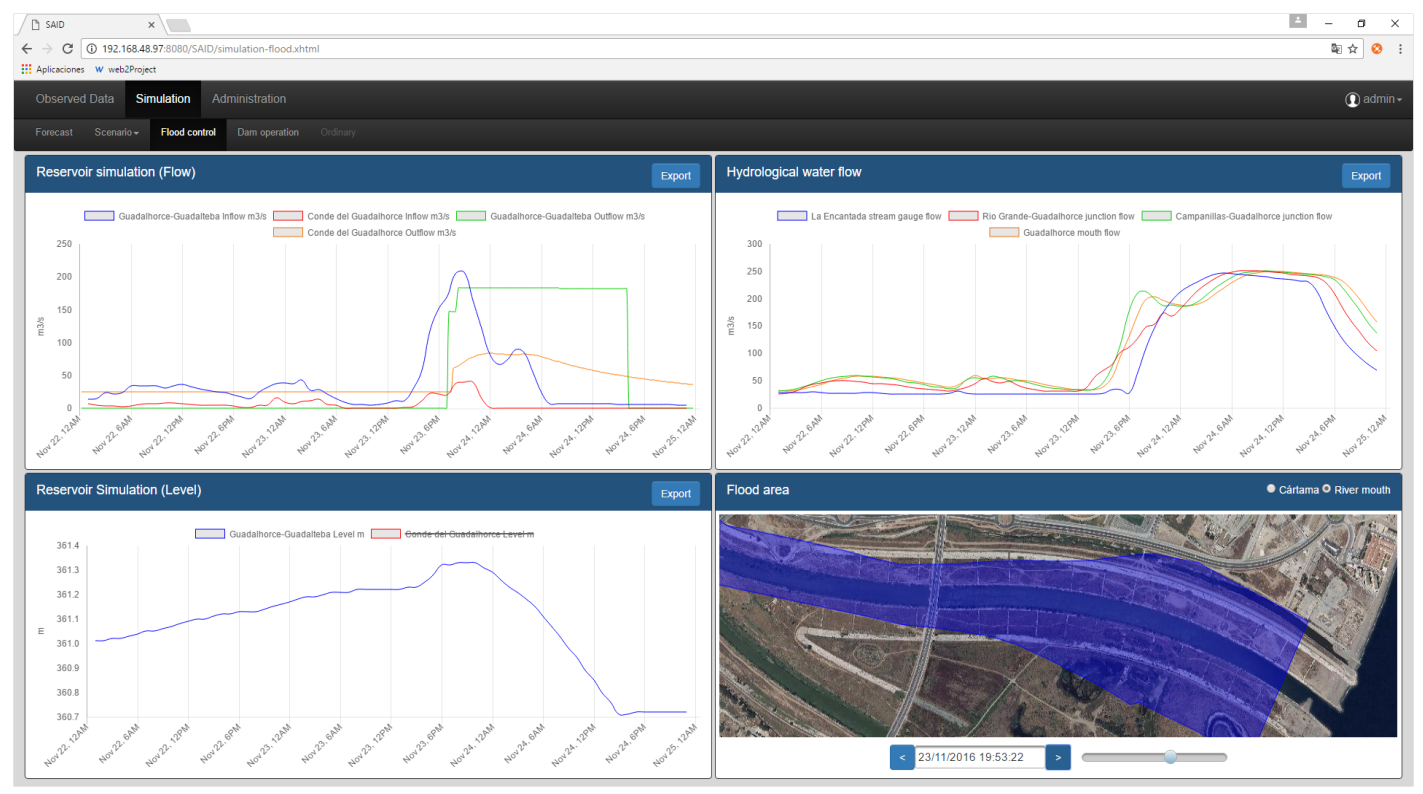

Figure 5: Results of Flood scenario (screenshot from Web Application)

The decision about classifying next hours as an ordinary or as a flood episode can be addressed in a semi-automatic way. A comparison between the estimated input hydrograph at the reservoirs and historical data of flow peaks in function of the month and flood return period (1-year, 5-years, 10years...) can be used as guidance. In any case, the user can select either flood or ordinary scenario regardless of the comparison results.

The ordinary scenario involves the combination of FM-DSS, WQ-DSS and EM-DSS to provide optimum reservoir exploitation that can satisfy the imposed constraints and fulfill the demand. Given the inflow to each reservoir (step one), the WQ-DSS determines the amount of water released from Dams 1 to 3 to achieve a certain level of salinity in the water mixture (see Figure 2(b)). The final salt concentration (considering Dam 1, 2 and 3 and the current salinity in Dam 4) is less restrictive for urban supply exclusively (normally in winter), and more limiting when both urban supply and irrigation are required (normally in summer, spring and autumn seasons). In the former case, water is mostly taken from Guadalhorce dam, the most salty reservoir, due to the existence of a desalination plant. In the latter case, the three reservoirs can potentially contribute to the mixture. The user is allowed to alter the objective salinity to face exceptional situations. The result of WQ-DSS describes the daily water volume that needs to be released from each reservoir to fulfill the demand under certain WQ constraints (see Figure 2(b)). WQ-DSS receives the inflow estimation and the daily water demand as an input. In addition, the tool internally accesses the shared XML files that contain the data gathered from the monitoring network.

The next action involves the use of EM-DSS to optimize energy production. This DSS determines the hourly distribution of the water volume release along the day, taking into account the constraints showed in Figure 2(b). Water releases depend on the operating hours of the power plants, which are determined by the volume of water released (variable factor) and their flow capacity (fixed factor). Moreover, this is influenced by staff availability, among others. The user can configure, if needed, the working hours of the plant in the Web application. Using the information of electricity prices, this DSS provides the most profitable release of water from each reservoir (Figure 6). 


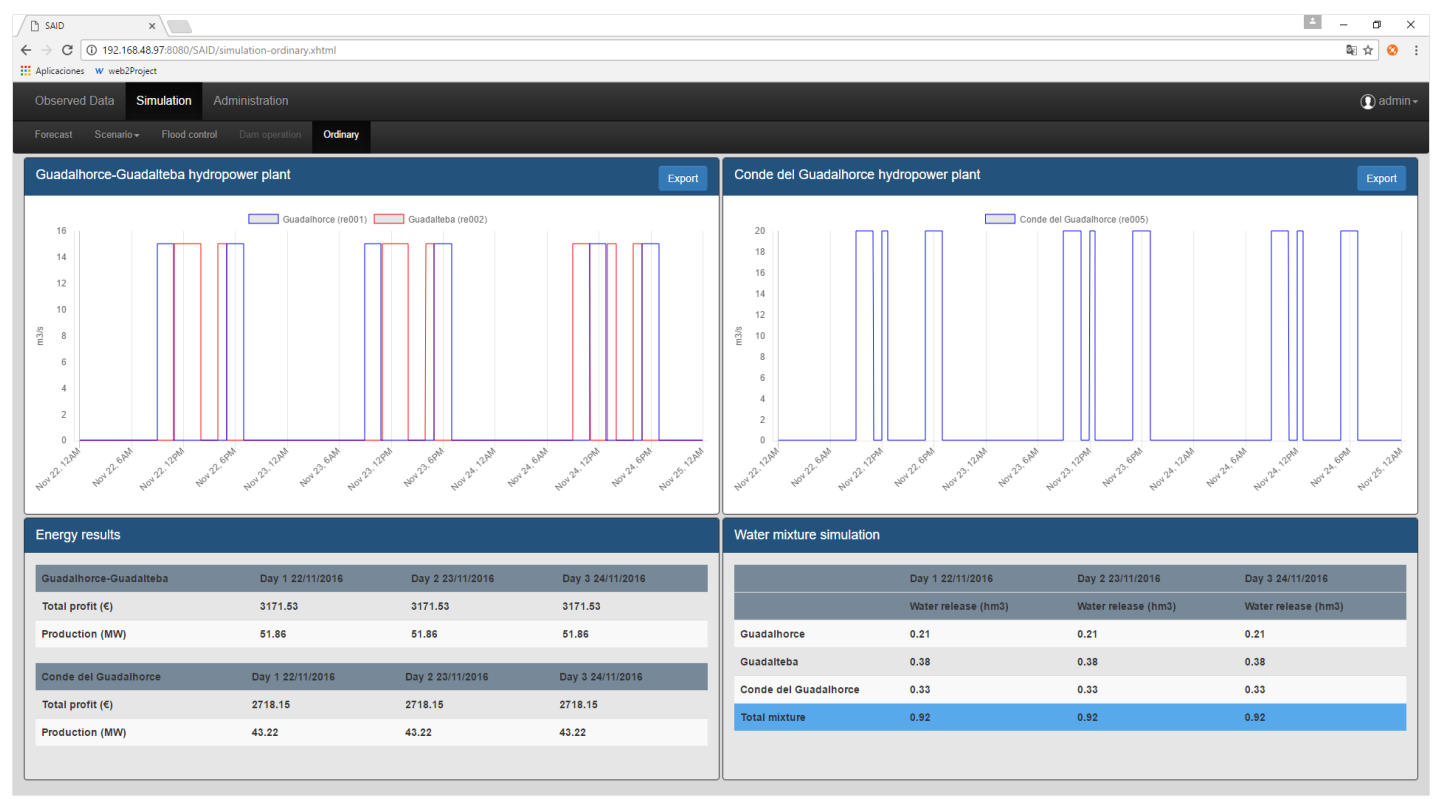

Figure 6: Results of Ordinary scenario (screenshot from Web Application)

\section{Conclusions}

The integrated DSS tool showed has developed knowledge and technologies that contributes to the sustainability of the integral water cycle. It has contributed to the efficient management of scarce resources through the development of a tool that takes into account the use of high quality information in real-time with climate prediction models.

The integrated platform developed gives dam managers the opportunity to assess the effects of their decisions in advance. The approach followed is flexible enough to support different tools and operation modes. The platform allows designing DSS to be implemented in the same system and interact with each other, enhancing management utilities. The DSS shares data input and work with more complex scenarios. Furthermore, the methodology can be applied to other river basins and isolated DSS software featuring different physical properties and software requirements, respectively.

The implementation of a suitable and automated water monitoring network and its integration as a module of the DSS has accounted for a more rational allocation of water supply demands, namely for irrigation, domestic and industrial purposes.

Policy makers can have access to data since the DSS permits extent information availability, data quality and empirical experiences that are extremely valuable to them, in order to implement local, national and EU regulations following the direction of the Water Framework Directive based on real indicators. 


\section{References}

Ahmadi, M., O. Bozorg Haddad, and M.A. Mariño. "Extraction of Flexible Multi-Objective RealTime Reservoir Operation Rules." Water Resources Management 28 (2014): 131-147.

Ahmed, J.A., and A.K. Sarma. "Genetic Algorithm for Optimal Operating Policy of a Multipurpose Reservoir." Water Resources Management 19 (2005): 145-161.

Bithel, M., and J. Brasington. "Coupling agent-based models of subsistence farming with individualbased forest models and dynamic models of water distribution." Environmental Modelling \& Software 24(2) (2009): 173-190.

Castelletti, A., D. de Rigo, A.E. Rizzoli, R. Soncini-Sessa, and E. Weber. "Neuro-dynamic programming for designing water reservoir network management policies." Control Engineering Practice 15 (2007): 1031-1038.

Egüen, M., et al. "WiMMed, a distributed physically-based watershed model (II): Application examples." Environmental Hydraulics: Theorical, Experimental \& Computational Solutions, 2009: 229-232. CRC Press/Balkema. ISBN 978-0-415-56697-1.

Herrero, J., A. Millares, C. Aguilar, A. Diaz, M.J. Polo, and M.A. Losada. WiMMed 1.0 Base teórica. Retrieved from Environmental Fluid Dynamics Research Group-CEAMA (University of Granada) and Fluvial Dynamics and Hydrology Research Group (University of Córdoba): http://www.uco.es/dfh/images/stories/20110614\%, 2011.

Linares, A., J. Regodón, L. Panizo, M.M. Gallardo, and P. Merino. "A DSS for reservoirs operation based on the execution of formal model." Internation Conference on Hydroinformatics. New York, 2014. 245.

Polo, M.J., et al. "WiMMed, a distributed physically-based watershed model (I): Description and validation." Environmental Hydraulics: Theorical Experimental \& Computational Solutions., 2009: 225-232. CRC Press/Balkema. ISBN 978-0-415-56697-1.

SAID Consortium. Final Report Summary - SAID (SmArt water management with Integrated Decision support systems). 2017. http://cordis.europa.eu/result/rcn/202618_en.html.

van Ittersum, M.K., et al. "Integrated assessment of agricultural systems - A component-based framework for the European Union (SEAMLESS)." Agricultural Systems 96 (2008): 150165.

Webber, J., S. Parastatidis, and I. Robinson. "REST in Practice." O'Reilly Medio, 2010.

Zatarain-Salazar, J., P.M. Reed, J.D. Herman, M. Giuliani, and A. Castelletti. "A diagnostic assessment of evolutionary algorithms for multi-objective surface water reservoir control." Advances in Water Resources 92 (2016): 172-185. 